\title{
Stability under stochastic perturbation of solutions of mathematical models of information spreading process with external control
}

\author{
Nakonechnyi O., Shevchuk I. \\ Taras Shevchenko National University of Kyiv, \\ 64/13 Volodymyrska Str., 01601, Kyiv, Ukraine
}

(Received 7 May 2018)

\begin{abstract}
In this paper mathematical model of spreading any number of information types with external influences is considered. The model takes the form of $n$ (number of information channels) non-linear Ito stochastic differential equations. Conditions for asymptotic stability in quadratic average in first-approximation of the special points are considered for general stationary model and special case with non-stationary parameters. The results of example are presented for the special case of the base model with stationary parameters.
\end{abstract}

Keywords: mathematical model of information spreading process, stochastic stability, asymptotic stability in quadratic average, "white" noise.

2000 MSC: 34D05

UDC: 517.9

DOI: $10.23939 / \mathrm{mmc} 2018.01 .066$

\section{Introduction}

In the last century opportunities of information for influence on members of social communities are begun to research. Scientists from different countries (USA, Great Britain, Russia and other) define the information spreading process as leading factor of internal and external socio-political processes. Since then work about information spreading process, its features, the possibility of using the process in own interests are showed up.

These researches have caused to need mathematical models of information spreading process one of the way to solve this problem is systems of ordinary differential equations.

Consider the basic model of spreading of any number of information messages in the society.

Let there be a certain social community of $N$ people, potentially subject $n$ information flows. At time moment $t_{0}=0$ community falls under influence one of the $N$ information channels. $x_{k}(t)$ are numbers of people who have accepted the information from the $k$-th information flow $(k=\overline{1, n})$. This value depends on external influences (media etc.) and interpersonal communication (internal influences).

There are $b_{k}, k=\overline{1, n}$ - the intensity of communication, $u_{k}$ are external influences. In this case we get

$$
\dot{x}_{k}(t)=b_{k}(t) x_{k}(t)\left(N-\sum_{i=1}^{n} x_{i}(t)\right)+u_{k}(t), \quad x_{k}(0)=x_{0 k}, \quad k=\overline{1, n} .
$$

Works [1-3] are devoted to analysis of solution oh this model (1) with stationary parameters and the special type of $u_{k}(t)$. Properties of solution of the system with the special type of $u_{k}(t)$ are analyzed in work [4]. Conditions of existence of range of first-approximation stability of the solutions are considered in [5]. Problems of building estimations of parameters of model (1) are investigated in $[6-10]$. 


\section{Stochastic stability in the first approximation of general model of information con- frontation}

Consider the case where the parameters are non-stationary and the external influences are simulated us

$$
u_{k}(t)=\sum_{i=1}^{n} a_{k i} x_{i}(t)+c_{k}, \quad k=\overline{1, n} .
$$

Then model (1) has the following form:

$$
\dot{x}_{k}(t)=b_{k} x_{k}(t)\left(N-\sum_{i=1}^{n} x_{i}(t)\right)+\sum_{i=1}^{n} a_{k i} x_{i}(t)+c_{k}, \quad x_{k}(0)=x_{0 k}, \quad k=\overline{1, n} .
$$

We assume that the parameters of the intensity of communication $b_{k}, k=\overline{1, n}$ are exposed disturbing influence. Them the model can be written as the system of Ito stochastic differential equations

$$
\begin{aligned}
d x_{k}(t)=\left[b_{k} x_{k}(t)\left(N-\sum_{i=1}^{n} x_{i}(t)\right)+\sum_{i=1}^{n} a_{k i} x_{i}(t)\right. & \left.+c_{k}\right] d t \\
& +g_{k} x_{k}(t)\left(N-\sum_{i=1}^{n} x_{i}(t)\right) d w_{k}(t), \quad k=\overline{1, n},
\end{aligned}
$$

with the initial conditions

$$
x_{k}(0)=x_{0 k}, \quad k=\overline{1, n},
$$

where $w_{k}(t)$ are Wiener processes, $d x_{k}(t)$ and $d w_{k}$ are stochastic differentials of processes $x_{k}(t)$ and $w_{k}(t), k=\overline{1, n}$ (in the sense of Ito).

Find the special point $\left(x_{10}, \ldots, x_{n 0}\right)$ for deterministic case of the system (3) from conditions

$$
\left\{\begin{array}{l}
L-\sum_{i=1}^{n} x_{i 0}=0 \\
\sum_{i=1}^{n} a_{k i} x_{i 0}+c_{k}=0, \quad k=\overline{1, n}
\end{array}\right.
$$

Let us rewrite the system of linear equations (4) in a matrix form

$$
\left(\begin{array}{cccc}
1 & 1 & \ldots & 1 \\
a_{11} & a_{12} & \ldots & a_{1 n} \\
\ldots & \ldots & \ldots & \ldots \\
a_{n 1} & a_{n 2} & \ldots & a_{n n}
\end{array}\right)\left(\begin{array}{c}
x_{10} \\
\ldots \\
x_{n 0}
\end{array}\right)=\left(\begin{array}{c}
L \\
-c_{1} \\
\ldots \\
-c_{n}
\end{array}\right)
$$

The sufficient condition of non-negative elements of the vector $\left(x_{10}, \ldots, x_{n 0}\right)$ is the existence of the matrix

$$
\left(\begin{array}{cccc}
1 & 1 & \ldots & 1 \\
a_{11} & a_{12} & \ldots & a_{1 n} \\
\ldots & \ldots & \ldots & \ldots \\
a_{n 1} & a_{n 2} & \ldots & a_{n n}
\end{array}\right)^{-1}
$$


On the basis of the Kronecker-Capelli theorem the linear system (5) has the unique solution if and only if the next condition is fulfilled

$$
\operatorname{rang}\left(\begin{array}{cccc}
1 & 1 & \ldots & 1 \\
a_{11} & a_{12} & \ldots & a_{1 n} \\
\ldots & \ldots & \ldots & \ldots \\
a_{n 1} & a_{n 2} & \ldots & a_{n n}
\end{array}\right)=\operatorname{rang}\left(\begin{array}{ccccc}
1 & 1 & \ldots & 1 & L \\
a_{11} & a_{12} & \ldots & a_{1 n} & -c_{1} \\
\ldots & \ldots & \ldots & \ldots & \ldots \\
a_{n 1} & a_{n 2} & \ldots & a_{n n} & -c_{n}
\end{array}\right)=n .
$$

Let us consider the linear approximation of the system (3) in neighbourhood of the special point $\left(x_{10}, \ldots, x_{n 0}\right)$

$$
\begin{aligned}
d x_{k}(t)=\left[b_{k}(N\right. & \left.\left.-\sum_{i=1}^{n} x_{i 0}\right)\left(x_{k}(t)-x_{k 0}\right)+\sum_{i=1}^{n}\left(a_{k i}-b_{k} x_{k 0}\right)\left(x_{i}(t)-x_{i 0}\right)\right] d t \\
& +g_{k}\left[\left(N-\sum_{i=1}^{n} x_{i 0}\right)\left(x_{k}(t)-x_{k 0}\right)-x_{k 0} \sum_{i=1}^{n}\left(x_{i}(t)-x_{i 0}\right)\right] d w_{k}(t), \quad k=\overline{1, n}
\end{aligned}
$$

Taking into account (4) from the system (8) we get

$$
d x_{k}(t)=\sum_{i=1}^{n}\left(a_{k i}-b_{k} x_{k 0}\right)\left(x_{i}(t)-x_{i 0}\right) d t-g_{k} x_{k 0} \sum_{i=1}^{n}\left(x_{i}(t)-x_{i 0}\right) d w_{k}(t), \quad k=\overline{1, n} .
$$

After replacement $\bar{x}_{k}(t)=x_{k}(t)-x_{k 0}, k=\overline{1, n}$ we get the system of linear Ito stochastic differential equations

$$
d \bar{x}_{k}(t)=\sum_{i=1}^{n}\left(a_{k i}-b_{k} x_{k 0}\right) \bar{x}_{i}(t) d t-g_{k} x_{k 0} \sum_{i=1}^{n} \bar{x}_{i}(t) d w_{k}(t), \quad k=\overline{1, n} .
$$

Let $\bar{x}(t)=\left(\bar{x}_{1}(t), \ldots, \bar{x}_{n}(t)\right)^{\mathrm{T}}, w(t)=\left(w_{1}(t), \ldots, w_{n}(t)\right)^{\mathrm{T}}$, $\mathrm{T}$ is the symbol of transpose than we can write the system (9) in matrix form

$$
d \bar{x}(t)=A \bar{x}(t) d t+\sum_{i=1}^{n} \bar{x}_{i}(t) B d w(t)
$$

where

$$
A=\left(\begin{array}{ccc}
a_{11}-b_{1} x_{10} & \ldots & a_{1 n}-b_{1} x_{10} \\
\ldots & \ldots & \ldots \\
a_{n 1}-b_{n} x_{n 0} & \ldots & a_{n n}-b_{n} x_{n 0}
\end{array}\right), \quad B=\left(\begin{array}{ccc}
-g_{1} x_{10} & \ldots & 0 \\
\ldots & \ldots & \ldots \\
0 & \ldots & -g_{n} x_{n 0}
\end{array}\right)
$$

Theorem 1. Let the condition of existence matrix (6) and condition (7) for system (3) are satisfied. The solutions of the system (3) are asymptotic stable in quadratic average in the first approximation in the area of special point $\left(x_{10}, \ldots, x_{n 0}\right)$ if and only if maximal eigenvalue of the matrix $C_{n}$ have negative real parts, where

$$
C_{n}=A+A^{\mathrm{T}}+\operatorname{Sp} B^{\mathrm{T}} B E_{n}
$$

and

$$
E_{n}=\left(\begin{array}{ccc}
1 & \ldots & 1 \\
\ldots & \ldots & \ldots \\
1 & \ldots & 1
\end{array}\right)
$$

is matrix of dimension $n \times n$. 
Proof. By definition the zero solutions $\bar{x}(t) \equiv 0$ of the system (9) is asymptotic stability in quadratic average if the next consider is fulfilled

$$
E(\bar{x}(t), \bar{x}(t)) \underset{t \rightarrow \infty}{\longrightarrow} 0,
$$

where $E$ the symbol of expected value.

On the basis of the Ito's lemma we obtain system of differential equations in matrix form

$$
\frac{d E(\bar{x}(t), \bar{x}(t))}{d t}=2 E(A \bar{x}(t), \bar{x}(t))+2 \frac{1}{2} E\left[\left(\sum_{i=1}^{n} \bar{x}_{i}(t)\right)^{2} \operatorname{Sp} B^{\mathrm{T}} B\right]
$$

with initial conditions

$$
E(\bar{x}(0), \bar{x}(0))=\sum_{i=1}^{n}\left(x_{0 k}-x_{k 0}\right)^{2} .
$$

Equation (11) we can be represented in the form

$$
\frac{d E(\bar{x}(t), \bar{x}(t))}{d t}=E\left(\left[A+A^{\mathrm{T}}+\operatorname{Sp} B^{\mathrm{T}} B E_{n}\right] \bar{x}(t), \bar{x}(t)\right) .
$$

Here is an estimate for equation (12)

$$
\lambda_{\min }\left(C_{n}\right) E(\bar{x}(t), \bar{x}(t)) \leqslant \frac{d E(\bar{x}(t), \bar{x}(t))}{d t} \leqslant \lambda_{\max }\left(C_{n}\right) E(\bar{x}(t), \bar{x}(t)),
$$

where $\lambda_{\min }\left(C_{n}\right)$ and $\lambda_{\max }\left(C_{n}\right)$ are minimal and maximal eigenvalues of the matrix $C_{n}$.

On the basis of Gronwall-Bellman inequality we obtain

$$
\exp \left\{\int_{0}^{t} \lambda_{\min }\left(C_{n}\right)\right\} E(\bar{x}(0), \overline{0}(t)) \leqslant E(\bar{x}(t), \bar{x}(t)) \leqslant \exp \left\{\int_{0}^{t} \lambda_{\max }\left(C_{n}\right)\right\} E(\bar{x}(0), \overline{0}(t)) .
$$

Because the parameters of the system (3) are stationary we have inequalities

$$
\exp \left\{\lambda_{\min }\left(C_{n}\right) t\right\} \sum_{i=1}^{n}\left(x_{0 k}-x_{k 0}\right)^{2} \leqslant E(\bar{x}(t), \bar{x}(t)) \leqslant \exp \left\{\lambda_{\max }\left(C_{n}\right) t\right\} \sum_{i=1}^{n}\left(x_{0 k}-x_{k 0}\right)^{2} .
$$

On the basis (13) the expression

$$
E(\bar{x}(t), \bar{x}(t)) \underset{t \rightarrow \infty}{\longrightarrow} 0
$$

is fulfilled if $\lambda_{\max }\left(C_{n}\right)$ have negative real parts. Thus the zero solution $\bar{x}(t) \equiv 0$ of the system (10) is asymptotic stable in quadratic average. The solutions of system (3) are asymptotic stable in quadratic average in the first approximation in the area of special point $\left(x_{10}, \ldots, x_{n 0}\right)$ if maximal eigenvalues of the matrix $C_{n}$ have negative real parts.

\section{Stochastic stability in the first approximation of special case of model of information confrontation}

Consider the special case of the system (1)

$$
\dot{x}_{k}(t)=\left(a_{k}(t)+b_{k}(t) x_{k}(t)\right)\left(N-\sum_{i=1}^{n} x_{i}(t)\right)+\gamma_{k}(t)\left(x_{k}(t)-m_{k} N\right), \quad x_{k}(0)=x_{0 k}, \quad k=\overline{1, n},
$$

where $m_{k} \geqslant 0, \quad \sum_{i=1}^{n} m_{i}=1$.

Mathematical Modeling and Computing, Vol.5, No.1, pp.66-73 (2018) 
And the parameters $b_{k}(t), k=\overline{1, n}$ are exposed disturbing influence, thus we obtain the system of Ito stochastic differential equations

$$
\begin{aligned}
d x_{k}(t)=\left[\left(a_{k}(t)+b_{k}(t) x_{k}(t)\right)\left(N-\sum_{i=1}^{n} x_{i}(t)\right)\right. & \left.+\gamma_{k}(t)\left(x_{k}(t)-m_{k} N\right)\right] d t \\
& +g_{k}(t) x_{k}(t)\left(N-\sum_{i=1}^{n} x_{i}(t)\right) d w_{k}(t), \quad k=\overline{1, n}
\end{aligned}
$$

with the initial conditions

$$
x_{k}(0)=x_{0 k}, \quad k=\overline{1, n} .
$$

The special point of system $(14)$ is $\left(m_{1} N, \ldots, m_{n} N\right)$. After linear approximation in neighbourhood of the special point and replacement $\bar{x}_{k}(t)=x_{k}(t)-m_{k} N, k=\overline{1, n}$ we get system of linear Ito stochastic differential equations in matrix form

$$
d \bar{x}(t)=A(t) \bar{x}(t) d t+\sum_{i=1}^{n} \bar{x}_{i}(t) B(t) d w(t),
$$

where

$$
\begin{gathered}
A(t)=\left(\begin{array}{ccc}
\gamma_{1}(t)-a_{1}(t)-b_{1}(t) m_{1} N & \ldots & -a_{1}(t)-b_{1}(t) m_{1} N \\
\ldots & \ldots & \ldots \\
-a_{n}(t)-b_{n}(t) m_{n} N & \ldots & \gamma_{n}(t)-a_{n}(t)-b_{n}(t) m_{n} N
\end{array}\right), \\
B(t)=\left(\begin{array}{ccc}
-g_{1}(t) m_{1} N & \ldots & 0 \\
\ldots & \ldots & \ldots \\
0 & \ldots & -g_{n}(t) m_{n} N
\end{array}\right) .
\end{gathered}
$$

Theorem 2. The solutions of the system (14) are asymptotic stable in quadratic average in the first approximation in the area of special point $\left(m_{1} N, \ldots, m_{n} N\right)$ if and only if condition $\frac{1}{t} \int_{0}^{t} \lambda_{\max }\left(D_{n}(\tau)\right) d \tau \leqslant-c, c>0, \forall t$ is satisfied, where $\lambda_{\max }\left(D_{n}(t)\right)$ is maximal eigenvalue of the matrix $D_{n}(t)$,

$$
D_{n}(t)=\frac{1}{2}\left[A(t)+A^{\mathrm{T}}(t)+\operatorname{Sp} B(t)^{\mathrm{T}} B(t) E_{n}+A^{*}(t)+\left(A^{\mathrm{T}}(t)\right)^{*}+\left(\operatorname{Sp} B^{\mathrm{T}}(t) B(t) E_{n}\right)^{*}\right],
$$

where $A^{*}(t)$ is conjugate transpose of matrix $A(t)$.

Proof. We need to find conditions of asymptotic stability in quadratic average of the zero solutions $\bar{x}(t) \equiv 0$ of the system (15).

On the basis of the Ito's lemma we obtain system of differential equations in matrix form

$$
\frac{d E(\bar{x}(t), \bar{x}(t))}{d t}=E\left(\left[A(t)+A^{\mathrm{T}}(t)+\operatorname{Sp} B^{\mathrm{T}}(t) B(t) E_{n}\right] \bar{x}(t), \bar{x}(t)\right),
$$

with initial conditions

$$
E(\bar{x}(0), \bar{x}(0))=\sum_{i=1}^{n}\left(x_{0 k}-m_{k} N\right)^{2} .
$$

In basis of Vazhevsky inequality [11] we obtain estimate for equation (16)

$$
\exp \left\{\int_{0}^{t} \lambda_{\min }\left(D_{n}(t)\right)\right\} E(\bar{x}(0), \overline{0}(t)) \leqslant E(\bar{x}(t), \bar{x}(t)) \leqslant \exp \left\{\int_{0}^{t} \lambda_{\max }\left(D_{n}(t)\right)\right\} E(\bar{x}(0), \overline{0}(t)) .
$$

Mathematical Modeling and Computing, Vol.5, No. 1, pp.66-73 (2018) 
Thus the zero solution $\bar{x}(t) \equiv 0$ of the system (15) is asymptotic stable in quadratic average if condition $\frac{1}{t} \int_{0}^{t} \lambda_{\max }\left(D_{n}(\tau)\right) d \tau \leqslant-c, c>0, \forall t$ is satisfied. The solutions of system (14) are asymptotic stable in quadratic average in the first approximation in the area of special point $\left(m_{1} N, \ldots, m_{n} N\right)$ if condition $\frac{1}{t} \int_{0}^{t} \lambda_{\max }\left(D_{n}(\tau)\right) d \tau \leqslant-c, c>0, \forall t$ is satisfied.

\section{Numerical experiment}

We obtain the special case of the system (14) when $n=2$ and parameters of model are stationary thus we obtain the system of Ito stochastic differential equations

$$
\begin{aligned}
& d x_{k}(t)=\left[\left(a_{k}+b_{k} x_{k}(t)\right)\left(N-x_{1}(t)-x_{2}(t)\right)+\gamma_{k}\left(x_{k}(t)-m_{k} N\right)\right] d t \\
& +g_{k} x_{k}(t)\left(N-x_{1}(t)-x_{2}(t)\right) d w_{k}(t), \quad m_{1}+m_{2}=1, \quad m_{k} \geqslant 0, \quad k=1,2 .
\end{aligned}
$$

After linear approximation in neighbourhood of the special point $\left(m_{1} N, m_{2} N\right)$ and replacement $\bar{x}_{k}(t)=x_{k}(t)-m_{k} N, k=\overline{1,2}$ we get system of linear Ito stochastic differential equations in matrix form

$$
d \bar{x}(t)=A \bar{x}(t) d t+\left(\bar{x}_{1}+\bar{x}_{2}\right) B d w(t)
$$

where

$$
A=\left(\begin{array}{cc}
\gamma_{1}-a_{1}-b_{1} m_{1} N & a_{1}-b_{1} m_{1} N \\
a_{2}-b_{2} m_{2} N & \gamma_{2}-a_{2}-b_{2} m_{2} N
\end{array}\right), \quad B=\left(\begin{array}{cc}
-g_{1} m_{1} N & 0 \\
0 & -g_{2} m_{2} N
\end{array}\right)
$$

On the basis of Theorem 1 the solutions of the system (17) are asymptotic stable in quadratic average in the first approximation in the area of special point $\left(m_{1} N, m_{2} N\right)$ if and only if all eigenvalues of the matrix $C_{2}$ have negative real parts, where

$$
\begin{gathered}
C_{2}=\left(\begin{array}{cc}
2\left(\gamma_{1}-a_{1}-b_{1} m_{1} N\right)+\operatorname{Sp} B^{\mathrm{T}} B & \operatorname{Sp} B^{\mathrm{T}} B-a_{1}-b_{1} m_{1} N-a_{2}-b_{2} m_{2} N \\
\operatorname{Sp} B^{\mathrm{T}} B-a_{1}-b_{1} m_{1} N-a_{2}-b_{2} m_{2} N & 2\left(\gamma_{2}-a_{2}-b_{2} m_{2} N\right)+\operatorname{Sp} B^{\mathrm{T}} B
\end{array}\right), \\
\operatorname{Sp} B^{\mathrm{T}} B=\left(g_{1} m_{1} N\right)^{2}+\left(g_{2} m_{2} N\right)^{2} .
\end{gathered}
$$

Thus the eigenvalues of the matrix $C_{2}$ have negative real parts if the next conditions are fulfilled $\left\{\begin{array}{l}\gamma_{1}+\gamma_{2}-a_{1}-b_{1} m_{1} N-a_{2}-b_{2} m_{2} N+\operatorname{Sp} B^{\mathrm{T}} B<0, \\ 4\left(\gamma_{1}-a_{1}-b_{1} m_{1} N\right)\left(\gamma_{2}-a_{2}-b_{2} m_{2} N\right)-\left(a_{1}+b_{1} m_{1} N+a_{2}+b_{2} m_{2} N\right)^{2}+2 \operatorname{Sp} B^{\mathrm{T}} B\left(\gamma_{1}+\gamma_{2}\right)>0 .\end{array}\right.$

As an example, we present the results of computer modeling of the dynamics of spreading two type of information.

Let there be a certain social community of $N=100$ people, potentially subject information flow. And we analysis the mathematical model on the time interval $(0,10)$.

Let parameters of the model satisfy $a_{1}=0.4, b_{1}=0.003, a_{2}=0.2, b_{2}=0.004, \gamma_{1}=-0.1$, $\gamma_{2}=-0.4, g_{1}=0.001, g_{2}=0.008, m_{1}=0.3, m_{2}=0.7$ and initial conditions are $x_{1}(0)=40$, $x_{2}(0)=20$.

Then the system (17) takes the form

$$
\left\{\begin{array}{c}
d x_{1}(t)=\left[\left(0.4+0.003 x_{1}(t)\right)\left(100-x_{1}(t)-x_{2}(t)\right)-0.1\left(x_{1}(t)-30\right)\right] d t \\
+0.001 x_{1}(t)\left(100-x_{1}(t)-x_{2}(t)\right) d w_{1}(t) \\
d x_{2}(t)=\left[\left(0.2+0.004 x_{2}(t)\right)\left(100-x_{1}(t)-x_{2}(t)\right)-0.4\left(x_{2}(t)-70\right)\right] d t \\
+0.008 x_{1}(t)\left(100-x_{1}(t)-x_{2}(t)\right) d w_{2}(t) \\
m_{1}+m_{2}=1, \quad m_{k} \geqslant 0, \quad k=1,2
\end{array}\right.
$$


The solutions of the system (18) are asymptotic stable in quadratic average in the first approximation in the area of special point $(30,70)$ because the conditions are fulfilled

$$
\left\{\begin{array}{c}
\gamma_{1}+\gamma_{2}-a_{1}-b_{1} m_{1} N-a_{2}-b_{2} m_{2} N+\operatorname{Sp} B^{\mathrm{T}} B=-1.156<0 \\
4\left(\gamma_{1}-a_{1}-b_{1} m_{1} N\right)\left(\gamma_{2}-a_{2}-b_{2} m_{2} N\right)-\left(a_{1}+b_{1} m_{1} N+a_{2}+b_{2} m_{2} N\right)^{2} \\
+2 \operatorname{Sp} B^{\mathrm{T}} B\left(\gamma_{1}+\gamma_{2}\right)=0.821>0
\end{array}\right.
$$

Results of numerical experiment for system (18) are presented in Fig. 1.
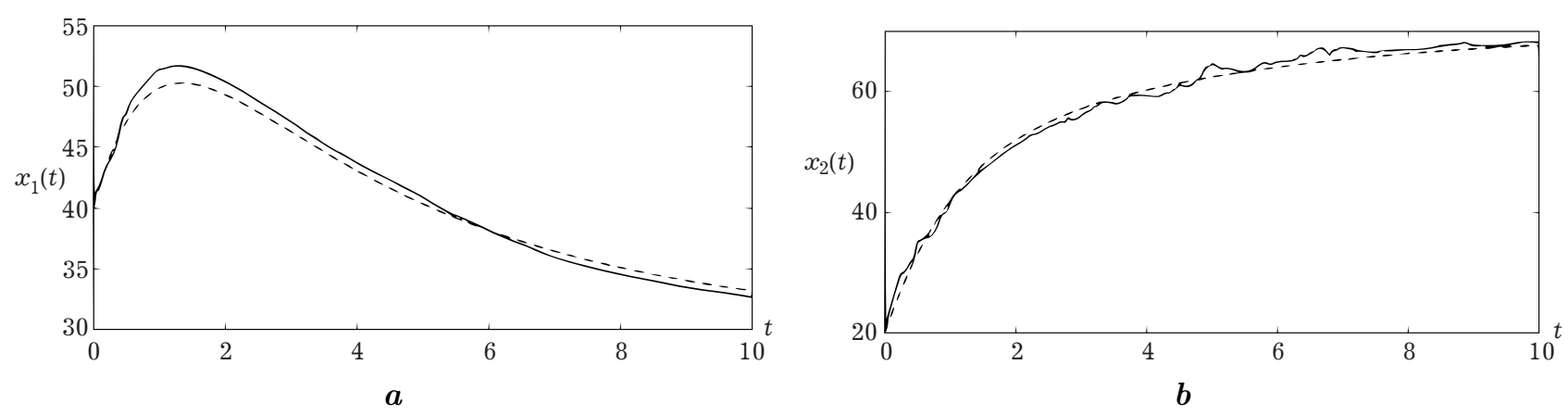

Fig. 1. The dynamics of the mathematical model (18); a) dynamic of first equation of the model (18) where solid curve is for $x_{1}(t)$, dotted curve is for dynamics of spreading first type of information without disturbing influence; $b$ ) dynamic of second equation of the model (18) where full line is $x_{2}(t)$, dotted curve is for dynamics of spreading second type of information without disturbing influence.

\section{Conclusions}

We have considered the mathematical models of information spreading process with a disturbing influence to the parameters of the system. The analysis is conducted using the first approximation in neighbourhood of the special point. This approach makes it possible to have conditions of asymptotic stable in quadratic average in the area of special point. The numerical experiment demonstrates the practical meaning of the offered results. These results can be used to choosing strategy, to select values of parameters (characteristic of actions) and to achieve desirable results.

[1] Mikhailov A. P., Marevtseva N. A. Models of Information Warfare. Mathematical Models and Computer Simulations. 3 (4), 251-259 (2012).

[2] Mikhailov A. P., Petrov A. P., Proncheva O. G., Marevtseva N. A. Mathematical Modeling of Information Warfare in a Society. Mediterranean Journal of Social Sciences. 6 (5), 27-35 (2015).

[3] Nakonechnyi O. G., Zinko P. M. Confrontation problems with the dynamics Gompertzian systems. Journal of Computational and Applied Mathematics. 3 (120), 50-60 (2015), (in Ukrainian).

[4] Nakonechnyi O. G., Shevchuk I. M. Mathematical model of information spreading process with nonstationary parameters. Bulletin of Taras Shevchenko National University of Kiev. Series Physics and Mathematics. 3, 98-105 (2016), (in Ukrainian).

[5] Shevchuk I. M. Stability of solutions of mathematical models of information spreading process with external control. Journal of Computational and Applied Mathematics. 1 (124), 99-111 (2017), (in Ukrainian).

[6] Nakonechnyi O. G. Best-mean estimates in models of information confrontation. Abstracts XXIV International Conference "Problem of decision making under uncertainties". Cesky Rudolec, Czech Republic. September 1-5. P. 114-115 (2014).

[7] Nakonechnyi O. G., Zinko P. M. Estimates of unsteady parameters in model of information confrontation. Abstracts XXVIII International Conference "Problem of decision making under uncertainties". Brno, Czech Republic. August 25-30. P. 82-83 (2016). 
[8] Nakonechnyi O. G., Zinko P. M., Shevchuk I. M. Averaged optimal predictive estimation of mathematical models of information spreading process under uncertainty. Bulletin of Taras Shevchenko National University of Kiev. Series Physics and Mathematics. 2, 122-127 (2017).

[9] Nakonechnyi O. G., Zinko P. M., Shevchuk I. M. Predictive estimation of mathematical models of information spreading process under uncertainty. System Research and Information Technologies. 4, 54-65 (2017), (in Ukrainian).

[10] Nakonechnyi O. G., Zinko P. M., Shevchuk I. M. Analysis of non-stationary mathematical models of information spreading process under uncertainty. Abstracts of International Scientific Conference "Modern Problems of Mathematical Modeling, Computational Mathematical Methods and Information Technologies". Rivne, Ukraine. P. 108-110 (2018), (in Ukrainian).

[11] Demidovich B. P. Lectures on the mathematical theory of stability. Moscow, Nauka (1967), (in Russian).

\title{
Стійкість під час стохастичних збурень розв'язків у математичних моделях розповсюдження інформації зі зовнішніми впливами
}

\author{
Наконечний О., Шевчук Ю. \\ Київсъкий начіональний університет імені Тараса Шевченка, \\ вул. Володимирсвка, 64/13, 01601, Київ, Україна
}

\begin{abstract}
Наведено загальну схему аналізу стохастичної стійкості за першим наближенням в околі точок стійкості моделі розповсюдження довільної кількості типів інформації на прикладах узагальненої моделі з стаціонарними параметрами та моделі з нестаціонарними параметрами та спеціальним представленням зовнішнього впливу. Результати числового експерименту демонструють практичні можливості цієї схеми. Отримані результати дали змогу визначати для параметрів моделі допустимі області, значення $з$ яких будуть гарантувати асимптотичну стійкість у середньоквадратичному за першим наближенням в околі стаціонарних точок.
\end{abstract}

Ключові слова: математична модель поширення інформачї̈, стохастична стійкість, асимптотична стійкість у середнвоквадратичному, "білий" шум.

2000 MSC: 34D05

УдК: 517.9

Mathematical Modeling and Computing, Vol.5, No.1, pp.66-73 (2018) 